\title{
Hemilaminectomia no tratamento de osteocondromatose vertebral em gato
}

\author{
Hemilaminectomy in the treatment of vertebral osteochondromatosis in a cat
}

\author{
Maria Lígia de Arruda Mistieri ${ }^{1}$ Vera Grevel $^{2}$ João Guilherme Padilha Filho ${ }^{3}$ \\ Paula Abi Rached ${ }^{1}$ Eberhard Ludewig ${ }^{2}$ Júlio Carlos Canola ${ }^{3}$
} \begin{abstract}
O termo osteocondromatose refere-se a
anormalidades proliferativas benignas de tecido cartilaginoso que
acomete ossos de origem endocondral. Esta condição pode ser
solitária ou múltipla e, neste último caso, é referida como exostose
múltipla cartilaginosa (EMC). Em felinos, é caracterizada pelo
surgimento em animais adultos e por apresentar desenvolvimento
progressivo. A osteocondromatose pode ser silenciosa e o paciente
poderá apresentar sinais clínicos quando o desenvolvimento das
exostoses resultar em compressão de estruturas vitais, como a
medula espinhal. Em felinos, a enfermidade não possui tratamento
conhecido devido ao seu caráter recidivante. Este trabalho relata
o êxito da aplicação de hemilaminectomia no tratamento de
osteocondromatose vertebral em gato. RESUMO
\end{abstract} Palavras-chave: exostose cartilaginosa múltipla, terapia, felino. ABSTRACT

Osteochondromatosis refers to benign proliferations of cartilaginous tissue ocurring in bones with endochondral development. This condition may be solitary or multiple and, in this case, is known as Multiple Cartilaginous Exostosis (MCE). In felines, usually occurs in adult animals and has progressive development. This disease can be silent until vital structures are not affected. No treatment is known in cats because of the high risk of recidives. This report shows the success of hemilaminectomy in the treatment of vertebral osteochondromatosis in a cat.

Key words: multiple cartilaginous exostosis, terapy, feline.

\section{INTRODUÇÃO}

A osteocondromatose corresponde à anormalidade proliferativa de tecido cartilaginoso que acomete os ossos originados de ossificação endocondral. Quando múltiplas lesões são encontradas em um mesmo indivíduo, a condição é referida como exostose múltipla catilaginosa (BECK et al., 1999). Esta afecção caracteriza-se, em felinos, pelo aparecimento em animais adultos e por desenvolvimento progressivo (MAGNUSSEN, 1997). Pode ser assintomática até que seu desenvolvimento resulte em compressão de estruturas vitais, como a medula espinhal (BECK et al., 1999).

O tratamento cirúrgico já foi aplicado em diversos casos ocorridos em cães, como relatam ACTON (1987) e JACOBSON \& KIRBERGER (1996). Porém, em gatos, a enfermidade não possui tratamento conhecido (SCHRADER \& SHERDING, 1994). O presente artigo relata a aplicação, com sucesso, de hemilaminectomia para o tratamento de compressão medular causada por osteocondromatose em gato.

Um felino da raça "Britain Short Hair”, de dois anos de idade, macho castrado, foi encaminhado por colega veterinário ao setor de policlínica do

${ }^{1}$ Bolsista do Conselho Nacional de Desenvolvimento Científico e Tecnológico, Programa de Pós-graduação em Cirurgia Veterinária, Faculdade de Ciências Agrárias e Veterinárias (FCAV), Universidade Estadual Paulista (UNESP), Rod. Carlos Tonanni, Km 5, 14870000, Jaboticabal, SP. E-mail para correspondência: malimistieri@yahoo.com.br.

${ }^{2}$ Professor titular da Policlínica de Pequenos Animais, Universidade de Leipzig, An den Tierkliniken, 1723, 04103- Leipzig, Alemanha. ${ }^{3}$ Professor assistente do Departamento de Clínica e Cirurgia Veterinária, FCAV, UNESP Jaboticabal. 
Hospital Veterinário da Universidade de Leipzig Alemanha, apresentando paraparesia. À anamnese, o proprietário informou que o animal mostrava sinais de apatia por cinco meses e há três meses já havia sido consultado naquela mesma instituição demonstrando sinais de dor de origem desconhecida, prostração e hipocalemia. Entretanto, nenhuma outra anormalidade foi observada e não foi possível concluir o diagnóstico.

O paciente apresentava-se alerta, com taquicardia, rigidez exacerbada na região dos músculos quadríceps e gastrocnêmio de ambos os membros, atrofia da musculatura lombar e pélvica e ataxia dos membros pélvicos, com ênfase no membro direito. Os membros pélvicos estavam flexionados e contraídos, com redução do reflexo de saltar e da propriocepção. Locomovia-se rastejando, abaixado e com extrema dificuldade. O reflexo patelar e dos flexores apresentavam-se normais, bem como o perineal e anal. O panículo inexistia a partir do segmento C8. Foi confirmada presença de dor profunda nestes membros. Os membros torácicos mantinham todos os reflexos normais.

O exame cardiológico e a perfusão dos membros posteriores não demonstraram nenhuma alteração. No hemograma e exame bioquímico completo, as únicas anormalidades consideráveis foram creatinina aumentada $\left(2,54 \mathrm{mg} \mathrm{dl}^{-1}\right)$ e ALT aumentado $\left(105,3 \mathrm{U} \mathrm{I}^{-1}\right)$. O exame do líquor apresentava-se normal.

A mielografia foi realizada através da injeção de contraste iopamidol (Solutrast 200M) no espaço L3-4 com dosagem de $0,3 \mathrm{ml} \mathrm{kg}^{-1}$ e auxílio de fluoroscopia. Por meio das projeções radiográficas látero-lateral e dorso-ventral foi possível a visibilização de compressão medular extradural localizada nas vértebras torácicas T1 e T2, de posição mais ventral e direcionada para o lado direito. Com a confirmação do diagnóstico de compressão medular entre T1 e T2, selecionaram-se novas possibilidades diagnósticas: neoplasia (osteocondromatose, leucose - forma epidural, metástase de carcinoma de próstata, metástase de tumor de mama, linfoma epitélio-neural, meningeoma), hematoma (baixa probabilidade pois tratava-se de um caso crônico), trauma com reação óssea e infecção (excluída após o resultado do exame de líquor). Devido à característica crônica da doença, a idade do animal, aos aspectos radiográficos e mielográficos das lesões, suspeitava-se principalmente de osteocondromatose.

Por se tratar de lesão ventro-lateralizada optou-se pela realização de hemilaminectomia, de acordo com a técnica descrita por WHEELER \&
SHARP (1999). A incisão foi realizada na linha média, na altura das primeira e segunda vértebras torácicas (T1 e T2). O afastamento lateral máximo dos músculos revelou a porção lateral direita das vértebras T1 e T2 em que foi possível a identificação da massa compressiva, de aspecto macroscópico compatível com osteocondromatose.

A hemilaminectomia foi realizada com auxílio de pinças-goiva e freza pneumática com remoção, inclusive, do processo articular entre T1 e $\mathrm{T} 2$, juntamente com a massa compressiva adjacente à vértebra. Foi observado que a exostose se projetava ventralmente, o que dificultava sua retirada completa. A medula espinhal foi exposta visibilizando-se a duramáter. O enxerto autógeno de gordura retirado do subcutâneo foi acomodado suavemente sobre a medula espinhal exposta. A musculatura, o tecido subcutâneo e a pele foram fechados como de rotina, evitando-se compressão demasiada sobre o enxerto de tecido gorduroso. Antibioticoterapia foi administrada nos cinco dias seguintes, com escolha de amoxicilina (20 $\mathrm{mg} \mathrm{kg}^{-1} \mathrm{BID}$ ) para tal. Também foi administrada metilprednisolona (20 $\left.\mathrm{mg} \mathrm{kg}^{-1} \mathrm{IV}\right)$. Fisioterapia foi realizada com utilização de movimentação passiva. O animal permaneceu sob os cuidados do corpo clínico do Hospital Veterinário de Leipzig pelo período de uma semana, quando já era possível a detecção do reflexo de panículo, mesmo que sutil. Foi aconselhado que os proprietários continuassem a realizar fisioterapia e que retornassem com o animal para controle radiográfico periódico.

\section{RESULTADOS E DISCUSSÃO}

A osteocondromatose é caracterizada pelo desenvolvimento de uma estrutura cartilaginosa encapsulada na superfície dos ossos formados por ossificação endocondral, não afetando ossos de origem intramembranosa (JACOBSON \& KIRBERGER, 1996). Segundo VANDEVELDE \& WOLF (1993) tal formação tem apresentação externa de consistência mole, porém possui uma porção central resistente e óssea e se expande a partir da superfície óssea afetada, cobrindo total ou parcialmente a mesma e substituindo sua cortical.

Sua etiopatogenia ainda não está totalmente esclarecida (LECOUTEUR \& CHILD, 1995; JACOBSON \& KIRBERGER, 1996). Uma hipótese a descreve como uma anormalidade de desenvolvimento do tipo condrodisplástico (BROWN et al., 1972; LECOUTEUR \& CHILD, 1995). Outras teorias incluiriam uma anormalidade na orientação do crescimento ósseo resultando em mudança na 
polaridade de algumas células cartilaginosas, displasia fiseal e distúrbio no periósteo. Em felinos, o Vírus da Leucemia Felina (FeLV) já foi implicado como agente causador (SCHRADER \& SHERDING, 1994).

A ocorrência em gatos, tanto da forma solitária como da múltipla, é ocasional e os locais de envolvimento mais freqüentes seriam: costelas, escápula, vértebras, crânio e pelve. Em lesões vertebrais, há predileção pela localização torácica e lombar (SCHRADER \& SHERDING, 1994; CAPORN \& READ, 1996). A forma solitária ocorre mais comumente em ossos longos, freqüentemente em animais maduros, na faixa etária de 2 a 4 anos (SCHRADER \& SHERDING, 1994), inclusive seu aparecimento e contínuo crescimento em animais adultos é característica da doença em felinos, como relata CAPORN \& READ (1996).

Clinicamente, a condição seria significativa devido à interferência com a locomoção e a tendência à transformação condrossarcomatosa (maligna) como descrito por GEE \& DOIGE (1970), a qual é estimada em 10 a 20\% em humanos (DOIGE, 1987). É válido comentar que a maioria dos casos são, sem dúvida, silenciosos e não diagnosticados (CAPORN \& READ, 1996). Radiograficamente, as exostoses parecem surgir da superfície óssea por uma base ampla. Mostram-se com aparência densa e com uma borda suavemente irregular, porém claramente definida (SCHRADER \& SHERDING, 1994.

À avaliação histológica, observa-se a existência de uma porção central de osso esponjoso com fina trabécula e tecido hematopoiético medular normal, que seria contínuo com a cavidade medular do osso no qual se originou. Macroscopicamente, a superfície é coberta por uma camada externa de cartilagem hialina e osso de espessuras variáveis. Ossificação endocondral é algumas vezes observada na porção cartilaginosa. Existe uma quantidade aumentada de tecido conectivo fibroso na interface da cortical do osso e as exostoses (WITTICK, 1990).

Segundo SELCER (1990), o tratamento depende da localização do problema e dos sinais clínicos a ele associados e que, geralmente, não é necessário a menos que ocorra compressão de medula espinhal. Entretanto, SCHRADER \& SHERDING (1994) mencionam que não se conhece tratamento para tal enfermidade em gatos, devido à característica recidivante da doença. JACOBSON \& KIRBERGER (1996) consideram o prognóstico desta enfermidade reservado à desfavorável.
Os sinais clínicos observados no animal descrito, causada pela compressão medular na altura das vértebras T1 e T2, não corresponde fielmente aos dados encontrados na literatura, os quais indicam que em um caso com tais características, seria observada uma hiporreflexia nos membros torácicos e hiperreflexia nos membros pélvicos (TOOMBS \& BAUER, 1993). Na realidade, o que se observou foi a presença de reflexos normais em todos os membros, com alteração no tônus muscular dos membros pélvicos, que estavam tensos, com perda de dor superficial e dificuldade de locomoção. O reflexo de panículo ausente a partir da região do segmento medular C8 corrobora com os dados mostrados também por TOOMBS \& BAUER (1993). Foi possível notar a recuperação parcial deste reflexo uma semana após o ato cirúrgico, quando o animal foi levado pelos proprietários.

O exame histopatológico não foi realizado neste último caso, mas nos dois casos anteriormente atendidos nesta mesma instituição, a confirmação diagnóstica foi obtida por este meio. Teste para FeLV foi realizado nestes três animais e todos os resultados foram negativos, contrariando a hipótese sugerida por SCHRADER \& SHERDING (1994) de que a osteocondromatose poderia ter etiologia viral. Um mês após a cirurgia, o paciente não se encontrava completamente recuperado e apresentava ainda dificuldade de locomoção. Este fato pode ser atribuído à posição tomada pela exostose, que se estendia para a porção ventral dos corpos vertebrais, o que impossibilitou a sua remoção completa (GREVEL 2001, informe verbal). Os proprietários foram avisados de que poderia ocorrer recidiva da afecção, de maneira que haveria necessidade de controle radiográfico periódico e biópsias para o controle de transformação maligna, segundo reportado por JACOBSON \& KIRBERGER (1996).

\section{CONCLUSÃO}

Embora CAPORN (1996) relate que não se conhece ainda nenhum tratamento para esta afecção em gatos, devido à característica de crescimento contínuo das exostoses nestes animais, este trabalho descreve a extirpação cirúrgica da neoplasia com melhora da qualidade de vida do animal e conseqüente aumento de sua sobrevida.

\section{INFORME VERBAL}

GREVEL, V. 2001. KliniK für Kleintiere, An den Tierkliniken, 23, Leipzig Universität, Leipzig- Alemanha.

Ciência Rural, v.34, n.6, nov-dez, 2004. 


\section{REFERÊNCIAS BIBLIOGRÁFICAS}

ACTON, C.E. Spinal cord compression in young dogs due to cartolaginous exostosis. Calif Vet, v.41, p.6-8, 1987.

BECK, J.A. et. al. Surgical management os ostheocondromatosis affecting the vertebrae and trachea in na Alaskan Malamute. Aust Vet, v.77, n.1, p.21-23, 1999.

BROWN, R.J. et. al. Multiple osteochondroma in a siamese cat. J Am Vet Med Assoc, v.160, n.4, p.433-435, 1972.

CAPORN, T.M.; READ, R.A. Case report Osteochondromatosis of the cervical spine causing compressive mielopathy in a dog. J Small Anim Pract, v.37, p.133-137, 1996.

DOIGE, C.E. Multiple exostosis in dogs. Vet Pathol, v.24, p.276-278, 1987.

GEE, B.R.; DOIGE, C.E. Multiple cartilaginous exostosis in a litter of dogs. J Am Vet Med Assoc, v.156, n.1, p.53-59, 1970.

JACOBSON, L.S.; KIRBERGER, R.M. Canine multiple cartilaginous exostosis: unusual manifestation and a review of literature. J Am Anim Hosp Assoc, v.32, p.4551, 1996.

LECOUTEUR, R.A.; CHILD, G. Spinal cord disease. In:
ETTINGER, S.J.; FELDMAN, E.C. Textbook of veterinary internal medicine. 4.ed. Philadelphia : Saunders, 1995. V.2, p.2089.

MAGNUSSEn, K.L. What is your diagnosis? J Am Vet Med Assoc, v.210, n.12, p.1733-1734, 1997.

SCHRADER, S.C.; SHERDING, R.G. Disorders of the skeletal system. In: SHERDING R.G. The cat diseases and clinical management. 2.ed. New York : Academic, 1994. V.2, p.15991647.

SELCER, R.R. What is your diagnosis? Progn Vet Neurol, v.1, p.340-342, 1990.

TOOMBS, J.P.; BAUER, M.S. Intervertebral disc disease. In: SLLATER, D. Textbook of small animal surgery. 2.ed. Philadelphia : Saunders, 1993. V.1, p.1080-1087.

VANDEVELDE, M.; WOLF, M. Spinal cord compression. In: BOJRAB, M.J. Disease mechanisms in small animal surgery. 2.ed. Philadelphia : Saunders, 1993. p.906-908, p.1152-1157.

WHEELER, S.J. SHARP, N.J.H. Diagnóstico e tratamento clínico cirúrgico das afecções espinhais do cão e do gato. São Paulo : Manole, 1999. 224p.

WHITTICK, W.G. Canine orthopaedics. 2.ed. Philadelphia: Saunders, 1990. p.857-894. 